\title{
OPEN Intraarticular triamcinolone hexacetonide, stanozolol, Hylan G-F 20 and platelet concentrate in a naturally occurring canine osteoarthritis model
}

\author{
J. C. Alves ${ }^{1,2 \bowtie}$, A. Santos ${ }^{1}$, P. Jorge ${ }^{1}$, C. Lavrador ${ }^{2}$ \& L. Miguel Carreira ${ }^{3,4,5}$
}

Osteoarthritis (OA) is a disease transversal to all mammals, a source of chronic pain and disability, a huge burden to societies, with a significant toll in healthcare cost, while reducing productivity and quality of life. The dog is considered a useful model for the translational study of the disease, closely matching human $O A$, with the advantage of a faster disease progression while maintaining the same life stages. In a prospective, longitudinal, double-blinded, negative controlled study, one hundred $(\mathrm{N}=100)$ hip joints were selected and randomly assigned to five groups: control group (CG, $n=20$, receiving a saline injection), triamcinolone hexacetonide group (THG, $n=20$ ), platelet concentrate group (PCG, $n=20)$, stanozolol group ( $S G, n=20$ ) and hylan $G-F 20$ group $(H G)$. Evaluations were conducted on days 0 (T0, treatment day), 8, 15, 30, 60, 90, 120, 150 and 180 days post-treatment, consisting of weight distribution analysis and data from four Clinical Metrology Instruments (CMI). Kaplan-Meier estimators were generated and compared with the Breslow test. Cox proportional hazard regression analysis was used to investigate the influence of variables of interest on treatment survival. All results were analyzed with IBM SPSS Statistics version 20 and a significance level of $p<0.05$ was set. Sample included joints of 100 pelvic limbs (of patients with a mean age of $6.5 \pm 2.4$ years and body weight of $26.7 \pm 5.2 \mathrm{~kg}$. Joints were graded as mild $(n=70)$, moderate $(n=20)$ and severe $(n=10)$ OA. No differences were found between groups at T0. Kaplan-Meier analysis showed that all treatments produced longer periods with better results in the various evaluations compared to CG. Patients in HG and PCG took longer to return to baseline values and scores. A higher impact on pain interference was observed in THG, with a 95\% improvement over CG. PCG and HG experienced $57-81 \%$ improvements in functional evaluation and impairments due to $O A$, and may be a better options for these cases. This study documented the efficacy of several approaches to relieve OA clinical signs. These approaches varied in intensity and duration. HG and PCG where the groups were more significant improvements were observed throughout the follow-up periods, with lower variation in results.

Osteoarthritis (OA) is a disease transversal to all mammals ${ }^{1}$. Being a source of chronic pain and disability, it represents a huge burden to societies, with a significant toll in healthcare cost, while reducing productivity and quality of life ${ }^{2,3}$. Its prevalence is expected to rise, due to a simultaneous increase in life expectancy and obesity ${ }^{4}$. The pathologic process, clinical presentation and response to treatment are very similar in humans and dogs, making the dog a frequent animal model for the study of osteoarthritis ${ }^{5}$. In fact, the changes that occur in slowly progressive spontaneous dog OA closely match those of human OA, with the added advantage of a faster disease progression while maintaining a juvenile, adolescent, adult and geriatric life stages. In addition, companion

${ }^{1}$ Divisão de Medicina Veterinária, Guarda Nacional Republicana (GNR), Rua Presidente Arriaga, 9, 1200-771 Lisbon, Portugal. ${ }^{2}$ MED - Mediterranean Institute for Agriculture, Environment and Development, Instituto de Investigação e Formação Avançada, Universidade de Évora, Pólo da Mitra, Ap. 94, 7006-554 Évora, Portugal. ${ }^{3}$ Faculty of Veterinary Medicine, University of Lisbon (FMV/ULisboa), Lisbon, Portugal. ${ }^{4}$ Interdisciplinary Centre for Research in Animal Health (CIISA) - University of Lisbon, (FMV/ULisboa), Lisbon, Portugal. ${ }^{5}$ Anjos of Assis Veterinary Medicine Centre (CMVAA), Barreiro, Portugal. ${ }^{\bowtie}$ email: alves.jca@gnr.pt 
animals share many of the same environmental conditions that their human counterparts. For those reasons the natural occurring canine model is considered an useful model of human OA, and exploring spontaneous canine OA can help improve human and dog health ${ }^{6-11}$.

The medical approach to OA aims at slowing disease progression while relieving symptoms, particularly pain, and improving overall function ${ }^{9,12}$. Imaging plays a key role in the assessment of patients with joint disease. In the case of hip OA, the ventrodorsal (VD) hip extended view is the most commonly performed radiographic view $^{13,14}$. This view is a valuable tool for evaluating the presence of hip $\mathrm{OA}^{15}$. Affected patients commonly bear less weight on an affected limb, since OA pain is related to movement or weight-bearing impairments of the affected joints. Evaluating weight distribution through stance analysis is a sensitive evaluation of lameness in $\operatorname{dogs}^{16-19}$. Weight distribution and off-loading or limb favouring at the stance are commonly used subjective assessments during the orthopaedic examination ${ }^{20}$. Dogs with OA may not be overtly lame at a walk or a trot but exhibit subtle shifts in body weight distribution at a stance due to pain ${ }^{18,21}$. Stance analysis has been reported as sensitive for detecting lameness in dogs, proposed to be an equivalent or superior measurement of pain associated with hip OA than vertical impulse and peak vertical force VI and $\mathrm{PVF}^{18}$. OA pain is a multi-dimensional experience, which encompasses more than just a functional aspect, and treatment interventions must address this reality ${ }^{17,22,23}$. Clinical metrology instruments (CMI) represent a patient-centred approach, and the most commonly used ones to evaluate dogs are the Canine Brief Pain Inventory (CBPI, divided in a pain severity score-PSS, and a pain interference score-PIS) and the Liverpool Osteoarthritis in Dogs (LOAD). In addition, the Hudson Visual Analogue Scale (HVAS), developed to assess the degree of lameness in dogs, and the Canine Orthopaedic Index (COI, divided in four scores: stiffness, gait, function and quality of life-QOL) are further validated CMIs which can complement the evaluation of the multi-dimensional, not directly measured experience that is OA related pain ${ }^{9,17,19,24-30}$.

IA therapies several advantages over systemic medications, as safety, especially when certain comorbidities are present, and bioavailability ${ }^{31}$. IA corticosteroids have been used for several decades to palliate pain and inflammation associated with OA and surrounding tissues ${ }^{32,33}$. Triamcinolone hexacetonide (TH), in particular, is described as able to provide pain relief and improved mobility for prolonged periods ${ }^{34,35}$. Autologous platelets are a regenerative treatment modality for $\mathrm{OA}$, used with the aim to stimulate the natural healing cascade and regeneration of tissues, through a supraphysiologic release of growth factors directly at the treatment site ${ }^{36-39}$. Stanozolol is a synthetic derivative of testosterone, and its properties include anabolic/androgenic activity ${ }^{40}$. When administered IA, it is able to induce fibroblasts to increase collagen production, decrease nitric oxide production and induce osteoblast proliferation and collagen synthesis ${ }^{41-44}$. It also has a chondroprotective and cartilage regeneration effect, while reducing osteophyte formation and subchondral bone reaction ${ }^{42,45}$. Even though hyaluronan's mechanism of action is not completely known and clinical trials have provided contradictory results, the aim of its use in the treatment of patients with OA is to reduce pain and improve function by supplementing the viscosity and elasticity of synovial fluid ${ }^{46,47}$. Additional anti-inflammatory, anti-nociceptive and chondroprotective properties have been suggested ${ }^{48,49}$. High molecular weight products seem to produce better results, particularly in patients with mild radiographic disease ${ }^{50,51}$.

In order to assess long-term outcomes and to identify factors associated with poorer outcome, we compared the effect of the intraarticular administration triamcinolone hexacetonide, hylan G-F 20, stanozolol and a platelet concentrate in the management of OA in a natural occurring canine model. We hypothesize that the different treatments will be able to reduce the clinical signs of OA, compared to a control group.

\section{Results}

The sample included 100 pelvic limbs ( $n=50$ left and $n=50$ right) of fifty active Police working dogs, with a mean age of $6.5 \pm 2.4$ years and body weight of $26.7 \pm 5.2 \mathrm{~kg}$, representing both sexes (male $n=60$, female $n=40)$. They were housed in kennels of the Portuguese Gendarmerie Canine Unit, similar in size. All dogs remained in active work during and after the study, and engaged in search and rescue, product detection and use of force mission. Active work and training were conducted on a daily basis, with their individual handlers. At T0, 70 joints were classified as mild, 20 as moderate and 10 as severe, according to the Orthopedic Foundation for Animals hip grading scheme. Values and scores of each evaluation in all groups at T0 are presented in Table 1 . No differences were found between groups at the initial evaluation $(\mathrm{p}=0.22$ for SI, $\mathrm{p}=0.075$ for deviation, $\mathrm{p}=0.12$ for HVAS, $p=0.23$ for PSS, $p=0.22$ for PIS, $p=0.07$ for LOAD, $p=0.48$ for stiffness, $p=0.10$ for function, $p=0.46$ for gait, $\mathrm{p}=0.25$ for QOL and $\mathrm{p}=0.21$ for COI).

All patients were followed up to the last evaluation moment (180 days) and, during this period, no additional treatment or medications was administered. Results of the Kaplan-Meier estimators with each evaluation method are presented in Table 2. All treatments showed longer periods with better results in the various evaluations compared to CG. Patients in HG and PCG, in particular, took longer to return to baseline values and scores. Results of the Cox proportional hazard regression are presented in Table 3. Increased lameness was observed in 16 patients in PCG, 8 in SG, 6 in HG and 4 in THG, which spontaneously resolved within 48-72 h.

\section{Discussion}

Osteoarthritis is a leading cause of disability around the world, which affects both the physical and mental wellbeing of populations. It poses a huge toll on healthcare resources and productivity ${ }^{52}$. Despite extensive research, still has limited treatment options available ${ }^{9,12}$. To our knowledge, this is the first prospective, negative controlled, double-blinded study to compare the effect of commonly used and novel IA treatments for the management of $\mathrm{OA}$, in a naturally occurring canine model, with a long follow up period.

Human reports on the effect of IA TH describe its long term safety, with improvements in joint range of motion and pain compared with a saline injection, with no differences between treatment with $40 \mathrm{mg}$ or $20 \mathrm{mg}$ 


\begin{tabular}{|l|c|l|l|l|l|}
\hline & CG & THG & HG & SG & PCG \\
\hline Weight $(\mathrm{kg}$. mean \pm SD) & $28.2 \pm 6.2$ & $26.5 \pm 6.5$ & $26.7 \pm 3.5$ & $27.1 \pm 3.2$ & $25.1 \pm 9.6$ \\
\hline Deviation $($ mean \pm SD) & $3.6 \pm 2.7$ & $4.7 \pm 4.4$ & $3.8 \pm 3.5$ & $4.3 \pm 3.5$ & $4.1 \pm 2.2$ \\
\hline Symmetry Index $($ mean \pm SD) & $24.8 \pm 26.5$ & $23.9 \pm 50.4$ & $21.7 \pm 24.9$ & $24.1 \pm 13.9$ & $22.6 \pm 12.4$ \\
\hline HVAS $(0-10)$ & $6.8 \pm 1.2$ & $5.7 \pm 1.9$ & $6.6 \pm 1.4$ & $6.7 \pm 1.3$ & $6.7 \pm 1.4$ \\
\hline PSS $(0-10)$ & $3.1 \pm 1.9$ & $4.2 \pm 2.8$ & $3.3 \pm 2.6$ & $2.9 \pm 1.5$ & $3.3 \pm 2.6$ \\
\hline PIS $(0-10)$ & $2.8 \pm 1.7$ & $4.8 \pm 3.3$ & $3.4 \pm 2.3$ & $2.3 \pm 1.7$ & $3.3 \pm 2.8$ \\
\hline LOAD $(0-52)$ & $13.6 \pm 10.5$ & $23.2 \pm 14.1$ & $17.0 \pm 10.5$ & $8.2 \pm 5.2$ & $13.3 \pm 11.3$ \\
\hline Stiffness $(0-16)$ & $3.4 \pm 3.4$ & $6.8 \pm 4.2$ & $3.4 \pm 2.9$ & $4.0 \pm 2.8$ & $3.9 \pm 3.9$ \\
\hline Function $(0-16)$ & $3.6 \pm 4.1$ & $6.3 \pm 5.7$ & $4.6 \pm 3.5$ & $4.0 \pm 3.6$ & $4.2 \pm 4.7$ \\
\hline Gait $(0-20)$ & $5.3 \pm 3.9$ & $10.5 \pm 5.9$ & $7.4 \pm 4.7$ & $5.2 \pm 3.9$ & $5.1 \pm 5.4$ \\
\hline QOL (0-12) & $4.3 \pm 2.5$ & $6.2 \pm 3.9$ & $4.5 \pm 3.1$ & $4.3 \pm 2.5$ & $4.5 \pm 3.6$ \\
\hline COI $(0-64)$ & $17.6 \pm 12.4$ & $19.8 \pm 19.1$ & $19.9 \pm 127$ & $17.5 \pm 12.4$ & $17.7 \pm 16.9$ \\
\hline
\end{tabular}

Table 1. Mean values ( \pm standard deviation) at initial evaluation of evaluation conducted for control and treatment groups. CG Control group, THG Triamcinolone hexacetonide group, HG Hylan G-F 20 group, $S G$ Stanozolol group, PCG Platelet concentrate group, HVAS Hudson Visual Analogue Scale, PSS Pain Severity Score, PIS Pain Interference Score, LOAD Liverpool Osteoarthritis in Dogs, QOL Quality of Life, COI Canine Orthopedic Index.

\begin{tabular}{|c|c|c|c|c|c|c|c|c|c|c|c|}
\hline \multirow[b]{3}{*}{ Variable } & \multirow[b]{3}{*}{ Breslow test } & \multicolumn{10}{|l|}{ Treatment } \\
\hline & & \multicolumn{2}{|l|}{ CG } & \multicolumn{2}{|l|}{ THG } & \multicolumn{2}{|l|}{ SG } & \multicolumn{2}{|l|}{ HG } & \multicolumn{2}{|l|}{ PCG } \\
\hline & & Mean \pm SD & $95 \% \mathrm{CI}$ & Mean \pm SD & $95 \% \mathrm{CI}$ & Mean \pm SD & $95 \% \mathrm{CI}$ & Mean \pm SD & $95 \% \mathrm{CI}$ & Mean \pm SD & $95 \% \mathrm{CI}$ \\
\hline Symmetry Index & $0.000^{*}$ & $47.0 \pm 11.8$ & $23.8-70.2$ & $96.0 \pm 12.8$ & $70.9-121.1$ & $94.2 \pm 15.9$ & $62.9-125.4$ & $104.1 \pm 15.1$ & \begin{tabular}{|l|}
$15.1-74.5$ \\
\end{tabular} & $159.0 \pm 10.3$ & $138.9-179.1$ \\
\hline Deviation & $0.000^{*}$ & $44.8 \pm 12.1$ & $21.1-68.5$ & $81.8 \pm 14.7$ & $52.9-110.6$ & $55.6 \pm 11.8$ & $32.3-78.8$ & $96.2 \pm 16.3$ & $64.2-128.1$ & $138.0 \pm 12.5$ & $113.4-162.6$ \\
\hline HVAS & $0.000^{*}$ & $48.7 \pm 12.4$ & $25.4-73.9$ & $66.1 \pm 14.2$ & $38.3-93.9$ & $129.8 \pm 13.4$ & $103.5-156.1$ & $117.0 \pm 13.2$ & $91.1-142.9$ & $144.0 \pm 11.6$ & $121.2-166.8$ \\
\hline PSS & $0.015^{*}$ & $63.2 \pm 17.2$ & $29.6-96.8$ & $90.2 \pm 17.6$ & $55.7-124.7$ & $94.6 \pm 16.4$ & $62.5-126.7$ & $142.6 \pm 11.9$ & $119.1-166.0$ & $150.5 \pm 9.7$ & $130.9-169.1$ \\
\hline PIS & $0.000^{*}$ & $8.4 \pm 0.4$ & \begin{tabular}{|l|}
$7.7-9.0$ \\
\end{tabular} & $118.6 \pm 16.3$ & $86.7-150.5$ & $109.6 \pm 17.3$ & $75.8-143.2$ & $114.0 \pm 16.0$ & $82.6-145.4$ & $135.0 \pm 10.6$ & $114.2-155.8$ \\
\hline LOAD & $0.000^{*}$ & $40.7 \pm 10.6$ & $19.9-61.4$ & $124.3 \pm 15.9$ & 93.1-155.5 & $123.8 \pm 14.2$ & 95.9-151.6 & $141.8 \pm 11.6$ & $119.2-164.4$ & $120.0 \pm 12.8$ & 94.9-145.0 \\
\hline Stiffness & $0.009^{*}$ & $64.7 \pm 16.9$ & $31.4-97.9$ & $130.8 \pm 11.6$ & $108.1-153.5$ & $111.2 \pm 15.9$ & $80.6-142.9$ & $129.8 \pm 13.9$ & $102.6-157.0$ & $141.0 \pm 16.9$ & $119.9-162.1$ \\
\hline Function & $0.000^{*}$ & $65.4 \pm 13.4$ & $39.2-91.6$ & $112.6 \pm 15.6$ & $81.9-143.2$ & $124.5 \pm 15.4$ & $94.2-154.8$ & $168.0 \pm 6.6$ & $155.1-180.8$ & $135.0 \pm 9.4$ & $116.5-153.5$ \\
\hline Gait & $0.001^{*}$ & $52.7 \pm 14.6$ & $23.9-81.4$ & $117.0 \pm 15.1$ & $87.5-146.5$ & $103.6 \pm 15.7$ & $72.8-134.4$ & $115.5 \pm 13.1$ & $89.9-141.1$ & $123.0 \pm 12.5$ & $98.5-147.5$ \\
\hline QOL & $0.004^{*}$ & $60.9 \pm 15.0$ & $31.4-90.4$ & $119.3 \pm 17.5$ & $85.0-153.6$ & $66.2 \pm 17.5$ & $31.8-100.6$ & $125.6 \pm 12.2$ & 101.6-149.6 & $120.8 \pm 13.1$ & $95.1-146.5$ \\
\hline COI & $0.011^{*}$ & $52.7 \pm 13.4$ & $26.5-78.9$ & $85.6 \pm 15.9$ & $54.4-116.9$ & $78.1 \pm 14.0$ & $50.6-105.6$ & $93.1 \pm 16.7$ & $60.3-125.9$ & $138.0 \pm 10.8$ & $116.9-159.1$ \\
\hline
\end{tabular}

Table 2. Survival probability calculated with Kaplan-Meier estimators and compared with the Breslow test. See Table 1 for legend. ${ }^{\star}$ Indicates significance.

of $\mathrm{TH}^{53-55}$. Previous reports on the effect of a single administration of a platelet concentrate showed improvements in pain, kinetics and joint range of motion, up to the last evaluation point considered, which ranged from 12 weeks to 6 months ${ }^{56,57}$. Different reports on the use of stanozolol in animals described it as being able to resolve signs of lameness, while reducing osteophyte formation, subchondral bone reaction, and promoting articular cartilage regeneration ${ }^{42,43}$. A previous study on a canine model has provided information on the efficacy of IA hyaluronan in animals with OA of pain, function, lameness and kinetics when compared to pre-treatment and saline control, with maximum benefits noted at 4-8 weeks and gradually tampered down by a 6-month evaluation time point ${ }^{58}$. OA is characterized by variable degrees of clinical and functional impairments, with the severity of pain correlating with the functional status rather than radiographic grading of osteoarthritis, which does not correlate with functional status. Treatment, therefore, could be planned according to the clinical features and functional status instead of radiological finding $s^{59,60}$. For that reason, we compared well established to novel therapeutic approaches, while evaluating the impact of documented predisposing and clinical factors of OA. All treatments were able to improve clinical signs of OA compared with the treatment groups, in all of the evaluated dimensions, from pain, function and quality of life. As a whole, patients in PCG and HG took longer to return to baseline values, which may indicate that these approaches are better therapeutic approaches for the management of OA. It was interesting to see that patients in the CG did not remained or returned to initial values and scores at the first follow-up evaluations, in some cases taking 60 days to do so. It has been documented that placebo saline injections may have an effect in functional improvements that can last up to a 6-month follow-up ${ }^{61}$, and a similar phenomenon may have occurred in this study.

We also investigated variables which could influence patient's response to treatment, regarding different OA dimensions. Age showed an impact in functional scores as HVAS, stiffness, gait and COI, as did the degree 


\begin{tabular}{|c|c|c|c|c|c|c|c|c|c|c|c|c|}
\hline \multirow[b]{3}{*}{ Variable } & \multicolumn{4}{|c|}{ Wheight distribution } & \multirow{2}{*}{\multicolumn{2}{|c|}{ HVAS $(p=0.000)$}} & \multicolumn{4}{|l|}{ CBPI } & \multirow{2}{*}{\multicolumn{2}{|c|}{$\operatorname{LOAD}(p=0.000)$}} \\
\hline & \multicolumn{2}{|c|}{$\begin{array}{l}\text { Symmetry Index } \\
(\mathbf{p = 0 . 0 0 8 )}\end{array}$} & \multicolumn{2}{|c|}{ Deviation $(p=0.024)$} & & & \multicolumn{2}{|c|}{ PSS $(p=0.412)$} & \multicolumn{2}{|c|}{ PIS $(p=0.000)$} & & \\
\hline & $\begin{array}{l}\text { HR }(95 \% \\
\text { CI) }\end{array}$ & $\mathbf{p}$ & $\begin{array}{l}\text { HR }(95 \% \\
\text { CI) }\end{array}$ & $\mathbf{p}$ & $\begin{array}{l}\text { HR }(95 \% \\
\text { CI) }\end{array}$ & $\mathbf{p}$ & $\begin{array}{l}\text { HR }(95 \% \\
\text { CI })\end{array}$ & $\mathbf{p}$ & $\begin{array}{l}\text { HR }(95 \% \\
\text { CI })\end{array}$ & $\mathbf{p}$ & $\begin{array}{l}\text { HR }(95 \% \\
\text { CI })\end{array}$ & $\mathbf{p}$ \\
\hline Age & $\begin{array}{l}0.91 \\
(0.83-10.01)\end{array}$ & 0.074 & $\begin{array}{l}0.95 \\
(0.86-1.05)\end{array}$ & 0.314 & $\begin{array}{l}1.13 \\
(1.02-1.25)\end{array}$ & $0.024^{\star}$ & $\begin{array}{l}1.08 \\
(0.97-1.21)\end{array}$ & 0.163 & $\begin{array}{l}0.95 \\
(0.86-1.06)\end{array}$ & 0.374 & \begin{tabular}{|l|}
0.93 \\
$(0.83-1.04)$
\end{tabular} & 0.190 \\
\hline Body weight & & & $\begin{array}{l}1.02 \\
(0.97-1.07)\end{array}$ & 0.509 & $\begin{array}{l}0.98 \\
(0.93-1.03)\end{array}$ & 0.378 & $\begin{array}{l}0.99 \\
(0.93-1.05)\end{array}$ & 0.770 & $\begin{array}{l}1.02 \\
(0.97-1.08)\end{array}$ & 0.479 & \begin{tabular}{|l|}
0.99 \\
$(0.94-1.06)$
\end{tabular} & 0.941 \\
\hline \multicolumn{13}{|l|}{ Sex } \\
\hline Male & 1.00 & & & & 1.00 & & 1.00 & & 1.00 & & 1.00 & \\
\hline Female & $\begin{array}{l}1.09 \\
(0.59-2.02)\end{array}$ & 0.763 & $\begin{array}{l}0.88 \\
(0.49-1.57)\end{array}$ & 0.657 & $\begin{array}{l}0.31 \\
(0.15-0.62)\end{array}$ & $0.001^{*}$ & $\begin{array}{l}1.24 \\
(0.64-2.38)\end{array}$ & 0.524 & $\begin{array}{l}1.12 \\
(0.61-2.08)\end{array}$ & 0.715 & $\begin{array}{l}1.18 \\
(0.63-2.21)\end{array}$ & 0.616 \\
\hline Treatment & & $0.002^{*}$ & & $0.005^{*}$ & & $0.003^{*}$ & & 0.154 & & $0.000^{*}$ & & $0.000^{*}$ \\
\hline Control & 1.00 & & & & 1.00 & & 1.00 & & 1.00 & & 1.00 & \\
\hline HG & \begin{tabular}{|l|}
0.53 \\
$(0.27-1.04)$
\end{tabular} & 0.067 & $\begin{array}{l}0.44 \\
(0.22-0.88)\end{array}$ & $0.020^{*}$ & $\begin{array}{l}0.27 \\
(0.12-0.63)\end{array}$ & $0.002^{*}$ & $\begin{array}{l}0.31 \\
(0.12-0.78)\end{array}$ & $0.013^{*}$ & \begin{tabular}{|l|}
0.07 \\
$(0.03-0.21)$
\end{tabular} & $0.000^{*}$ & $\begin{array}{l}0.11 \\
(0.04-0.28)\end{array}$ & $0.000^{*}$ \\
\hline PCG & $\begin{array}{l}0.20 \\
(0.93-0.45)\end{array}$ & $0.000^{*}$ & $\begin{array}{l}0.31 \\
(0.15-0.62)\end{array}$ & $0.001^{*}$ & $\begin{array}{l}0.26 \\
(0.12-0.56)\end{array}$ & $0.001^{*}$ & $\begin{array}{l}0.53 \\
(0.24-1.16)\end{array}$ & 0.114 & \begin{tabular}{|l|}
0.09 \\
$(0.03-0.24)$
\end{tabular} & $0.000^{*}$ & $\begin{array}{l}0.31 \\
(0.15-0.64)\end{array}$ & $0.001^{*}$ \\
\hline SG & \begin{tabular}{|l|}
0.39 \\
$(0.19-0.82)$ \\
\end{tabular} & $0.012^{*}$ & $\begin{array}{l}0.85 \\
(0.44-1.66) \\
\end{array}$ & 0.642 & $\begin{array}{l}0.33 \\
(0.14-0.77)\end{array}$ & $0.010^{*}$ & $\begin{array}{l}0.57 \\
(0.25-1.33)\end{array}$ & 0.195 & \begin{tabular}{|l}
0.08 \\
$(0.03-0.23)$
\end{tabular} & $0.000^{*}$ & \begin{tabular}{|l|}
0.17 \\
$(0.07-0.37)$
\end{tabular} & $0.000^{*}$ \\
\hline THG & $\begin{array}{l}0.46 \\
(0.22-0.96)\end{array}$ & $0.039^{*}$ & $\begin{array}{l}0.43 \\
(0.21-0.89)\end{array}$ & $0.023^{*}$ & $\begin{array}{l}0.98 \\
(0.93-1.03)\end{array}$ & 0.151 & $\begin{array}{l}0.70 \\
(0.31-1.59)\end{array}$ & 0.397 & $\begin{array}{l}0.05 \\
(0.02-0.14)\end{array}$ & $0.000^{*}$ & \begin{tabular}{|l|}
0.09 \\
$(0.94-1.06)$
\end{tabular} & $0.000^{*}$ \\
\hline OFA score & & 0.831 & & 0.179 & & $0.026^{*}$ & & & & 0.175 & & $0.007^{*}$ \\
\hline Mild & 1.00 & & & & 1.00 & & 1.00 & & 1.00 & & 1.00 & \\
\hline Moderate & \begin{tabular}{|l|}
0.85 \\
$(0.45-1.58)$
\end{tabular} & 0.605 & $\begin{array}{l}1.01 \\
(0.57-1.80)\end{array}$ & 0.973 & $\begin{array}{l}1.29 \\
(0.68-2.47)\end{array}$ & 0.435 & $\begin{array}{l}1.09 \\
(0.58-2.03)\end{array}$ & 0.79 & $\begin{array}{l}1.74 \\
(0.95-3.19)\end{array}$ & 0.074 & $\begin{array}{l}2.93 \\
(1.50-5.70)\end{array}$ & $0.002^{*}$ \\
\hline Severe & $\begin{array}{l}1.11 \\
(0.47-2.62)\end{array}$ & 0.811 & $\begin{array}{l}2.21 \\
(0.95-5.2)\end{array}$ & 0.67 & $\begin{array}{l}3.46 \\
(1.39-8.55)\end{array}$ & $0.007^{*}$ & $\begin{array}{l}0.79 \\
(0.25-2.5)\end{array}$ & 0.70 & \begin{tabular}{|l|}
0.86 \\
$(0.29-2.5)$
\end{tabular} & 0.784 & \begin{tabular}{|l|}
1.56 \\
$(0.49-4.92)$
\end{tabular} & 0.451 \\
\hline & \multicolumn{12}{|l|}{ COI } \\
\hline & \multicolumn{2}{|c|}{ Stiffness $(p=0.001)$} & \multicolumn{2}{|c|}{ Function $(p=0.000)$} & \multicolumn{2}{|c|}{ Gait $(p=0.000)$} & \multicolumn{2}{|c|}{ QOL $(p=0.033)$} & \multicolumn{4}{|c|}{ Total $(\mathrm{p}=0.000)$} \\
\hline Variable & $\begin{array}{l}\text { HR }(95 \% \\
\text { CI })\end{array}$ & $\mathbf{p}$ & $\begin{array}{l}\text { HR }(95 \% \\
\text { CI) }\end{array}$ & $\mathbf{p}$ & $\begin{array}{l}\text { HR }(95 \% \\
\text { CI })\end{array}$ & $\mathbf{P}$ & $\begin{array}{l}\text { HR }(95 \% \\
\text { CI })\end{array}$ & $\mathbf{p}$ & $\begin{array}{l}\text { HR }(95 \% \\
\text { CI })\end{array}$ & $\mathbf{p}$ & & \\
\hline Age & $\begin{array}{l}1.19 \\
(1.05-1.35)\end{array}$ & $0.007^{\star}$ & $\begin{array}{l}1.09 \\
(0.99-1.21)\end{array}$ & 0.093 & $\begin{array}{l}1.27 \\
(1.13-1.43)\end{array}$ & $0.000^{*}$ & $\begin{array}{l}0.98 \\
(0.88-0.11)\end{array}$ & 0.835 & \begin{tabular}{|l|}
1.15 \\
$(1.04-1.26)$ \\
\end{tabular} & $0.005^{*}$ & & \\
\hline Body weight & $\begin{array}{l}1.03 \\
(0.97-1.09)\end{array}$ & 0.324 & $\begin{array}{l}1.03 \\
(0.97-1.09)\end{array}$ & 0.346 & $\begin{array}{l}1.01 \\
(0.96-1.07)\end{array}$ & 0.717 & $\begin{array}{l}1.04 \\
(0.99-1.10)\end{array}$ & 0.106 & $\begin{array}{l}0.98 \\
(0.93-1.05)\end{array}$ & 0.603 & & \\
\hline \multicolumn{13}{|l|}{ Sex } \\
\hline Male & 1.00 & & 1.00 & & 1.00 & & 1.00 & & 1.00 & & & \\
\hline Female & $\begin{array}{l}2.02 \\
(0.99-4.09)\end{array}$ & 0.051 & $\begin{array}{l}1.40 \\
(0.74-2.67)\end{array}$ & 0.304 & $\begin{array}{l}1.28 \\
(0.67-2.45)\end{array}$ & 0.453 & $\begin{array}{l}2.58 \\
(1.33-5.01)\end{array}$ & $0.005^{*}$ & $\begin{array}{l}1.79 \\
(0.95-3.37)\end{array}$ & 0.071 & & \\
\hline Treatment & & $0.032^{*}$ & & $0.000^{*}$ & & $0.002^{*}$ & & 0.303 & & $0.012^{*}$ & & \\
\hline Control & 1.00 & & 1.00 & & 1.00 & & 1.00 & & 1.00 & & & \\
\hline HG & $\begin{array}{l}0.25 \\
(0.09-0.64)\end{array}$ & $0.004^{*}$ & $\begin{array}{l}0.09 \\
(0.03-0.27)\end{array}$ & $0.000^{*}$ & $\begin{array}{l}0.16 \\
(0.06-0.42)\end{array}$ & $0.000^{*}$ & $\begin{array}{l}0.45 \\
(0.19-1.05)\end{array}$ & 0.064 & \begin{tabular}{|l|}
0.41 \\
$(0.19-0.90)$
\end{tabular} & $0.026^{*}$ & & \\
\hline PCG & $\begin{array}{l}0.34 \\
(0.15-0.79)\end{array}$ & $0.012^{*}$ & $\begin{array}{l}0.40 \\
(0.19-0.81)\end{array}$ & $0.011^{*}$ & $\begin{array}{l}0.28 \\
(0.13-0.61)\end{array}$ & $0.001^{*}$ & $\begin{array}{l}0.55 \\
(0.26-1.15)\end{array}$ & 0.113 & $\begin{array}{ll}0.28 \\
(0.13-0.59)\end{array}$ & $0.001^{*}$ & & \\
\hline SG & $\begin{array}{l}0.41 \\
(0.16-1.02)\end{array}$ & 0.054 & $\begin{array}{l}0.27 \\
(0.11-0.66)\end{array}$ & $0.004^{*}$ & $\begin{array}{l}0.45 \\
(0.19-1.03)\end{array}$ & 0.058 & $\begin{array}{l}0.92 \\
(0.45-1.85)\end{array}$ & 0.808 & \begin{tabular}{|l|}
0.53 \\
$(0.24-1.14)$
\end{tabular} & 0.103 & & \\
\hline THG & \begin{tabular}{|l|}
0.34 \\
$(0.14-0.80)$
\end{tabular} & $0.014^{\star}$ & $\begin{array}{l}0.33 \\
(0.15-0.73)\end{array}$ & $0.006^{*}$ & $\begin{array}{l}0.32 \\
(0.15-0.69)\end{array}$ & $0.004^{*}$ & $\begin{array}{l}0.69 \\
(0.32-1.47)\end{array}$ & 0.333 & \begin{tabular}{|l|}
0.39 \\
$(0.18-0.85)$
\end{tabular} & $0.018^{*}$ & & \\
\hline OFA score & & 0.0159 & & $0.014^{\star}$ & & 0.081 & & 0.338 & & $0.048^{*}$ & & \\
\hline Mild & 1.00 & & 1.00 & & 1.00 & & 1.00 & & 1.00 & & & \\
\hline Moderate & \begin{tabular}{|l|}
0.97 \\
$(0.49-1.89)$
\end{tabular} & 0.936 & $\begin{array}{l}1.07 \\
(0.54-2.14)\end{array}$ & 0.841 & $\begin{array}{l}0.66 \\
(0.34-1.28)\end{array}$ & 0.222 & $\begin{array}{l}0.81 \\
(0.44-1.47)\end{array}$ & 0.477 & \begin{tabular}{|l|}
0.61 \\
$(0.33-1.15)$
\end{tabular} & 0.127 & & \\
\hline Severe & $\begin{array}{l}2.48 \\
(0.94-6.59)\end{array}$ & 0.068 & $\begin{array}{l}4.59 \\
(1.65-12.82)\end{array}$ & $0.004^{\star}$ & $\begin{array}{l}2.11 \\
(0.79-5.58)\end{array}$ & 0.134 & $\begin{array}{l}1.75 \\
(0.67-4.55)\end{array}$ & 0.252 & $\begin{array}{l}2.17 \\
(0.86-5.45)\end{array}$ & 0.101 & & \\
\hline
\end{tabular}

Table 3. Results Cox proportional hazard regression with the different outcome evaluations. See Table 1 for legend. ${ }^{\star}$ Indicates significance.

of OA, with patients with severe OA showing an impact on HVAS and function score. These findings could be explained with the fact that $\mathrm{OA}$ is a progressive, degenerative disease, which ultimately has a toll on joint function, without, however, a corresponding increase in pain levels. It is also well established that individuals with higher body mass index experience greater pain than individuals with lower index ${ }^{62}$. We evaluated the effect of 


\begin{tabular}{|c|c|c|c|c|c|c|c|c|c|}
\hline \multirow[b]{2}{*}{ Procedure } & \multicolumn{9}{|c|}{ Day } \\
\hline & 0 & 8 & 15 & 30 & 60 & 90 & 120 & 150 & 180 \\
\hline Treatment & $\mathrm{X}$ & & & & & & & & \\
\hline Stance analysis & $\mathrm{X}$ & $\mathrm{X}$ & $\mathrm{X}$ & $\mathrm{X}$ & & $\mathrm{X}$ & & & $\mathrm{X}$ \\
\hline Digital radiography & $\mathrm{X}$ & & & $\mathrm{x}$ & & $\mathrm{X}$ & & & $\mathrm{X}$ \\
\hline HVAS & $\mathrm{X}$ & $\mathrm{X}$ & $\mathrm{X}$ & $\mathrm{X}$ & $\mathrm{X}$ & $\mathrm{X}$ & $\mathrm{X}$ & $\mathrm{X}$ & $\mathrm{X}$ \\
\hline CBPI & $\mathrm{X}$ & $\mathrm{X}$ & $\mathrm{X}$ & $\mathrm{X}$ & $\mathrm{X}$ & $\mathrm{X}$ & $\mathrm{X}$ & $\mathrm{X}$ & $\mathrm{X}$ \\
\hline COI & $\mathrm{X}$ & $\mathrm{X}$ & $\mathrm{X}$ & $\mathrm{X}$ & $\mathrm{X}$ & $\mathrm{X}$ & $\mathrm{X}$ & $\mathrm{X}$ & $\mathrm{X}$ \\
\hline LOAD & $\mathrm{X}$ & $\mathrm{X}$ & $\mathrm{X}$ & $\mathrm{X}$ & $\mathrm{X}$ & $\mathrm{X}$ & $\mathrm{X}$ & $\mathrm{X}$ & $\mathrm{X}$ \\
\hline
\end{tabular}

Table 4. Procedures conducted in each evaluation moment. Days are counted from treatment day. CBPI Canine Brief Pain Inventory, COI Canine Orthopedic Index, HVAS Hudson Visual Analogue Scale, $L O A D$ Liverpool Osteoarthritis in Dogs.

body weight in the evolution of OA, which is not the same as body mass index, but since patients in this sample were working dogs, with an ideal body condition score, we chose to evaluate body weight instead which did not influenced any of the evaluation made.

Comparing the effect of different treatments, as a whole they had an effect on all dimensions evaluated, except PSS. Reasons for that may be related with the nature of these animals are working dogs and, for that reason, tend to show few signs of overt pain. In fact, pain is more easily and commonly detected through its impact on measurable parameters, such as weigh bearing, or on active exercises ${ }^{57}$. This may be reflected on an effect of different treatments on the PIS score, but not on the PSS score. PCG and HG registered effects for longer periods, and better improvements according to the Cox hazard regression with the different evaluations made. Considering measurable parameters, patients in PCH showed an $81 \%$ and $69 \%$ improvement in SI and deviation, respectively, while HG showed $61 \%$ and $57 \%$ improvements. These seem to be the preferred treatments for functional impairments due to OA. In addition to these evaluations, PCG and HG also registered greater improvements in several scores as HVAS, stiffness, function, gait and COI. Better impact on pain interference was observed in THG, which could be attributed to the high anti-inflammatory effect of corticosteroids, and the relation between pain and inflammation.

Side effects related after IA treatment are documented, and usually include injection pain and local inflammation, that take 2-10 days to resolve $e^{43,58,63,64}$. We observed increased lameness in all groups, which spontaneously resolved within 48-72 h.

This study presents some limitations, namely the inclusion of two joints from each dogs, as an association may occur between limbs. This effect has been described in humans ${ }^{65,66}$. Still, the inclusion of contralateral limbs from the same patient is common in animal models, even for the calculation of a symmetry index ${ }^{27,42,58}$. A reason for this is that quadrupeds show more complex compensation mechanism than just side-to-side. Results from the weight bearing evaluation of the patients of this study show that the major compensation occurs in the contralateral thoracic limb, rather than side-to-side. In addition, a majority of joints considered in this study had mild OA. Further studies should include a larger number of the remaining hip grades to determine if similar results are obtained. The safety and efficacy of repeated IA injections should also be investigated.

\section{Conclusions}

To our knowledge, this is the first prospective, negative controlled, double-blinded study to compare the effect of commonly used and novel IA treatments for the management of OA, in a naturally occurring canine model, with a long follow up period. It provides important information for the characterization of the effects of these treatment modalities, duration of observed improvements function and pain, in addition to information regarding candidates for each one.

\section{Methods}

The study protocol was approved by the ethical review committee of the University of Évora (Órgão Responsável pelo Bem-estar dos Animais da Universidade de Évora, approval no GD/32055/2018/P1, September 25th, 2018), and complies with ARRIVE guidelines. All experiments were performed in accordance with relevant guidelines and regulations. Written, informed consent was obtained from the Institution responsible for the animals. In a prospective, longitudinal, double-blinded, negative controlled study, patients were selected after screening of the Portuguese Gendarmerie Canine Unit, based on history, physical, orthopedic, neurological and radiographic examinations compatible with bilateral hip OA. The sample comprised one hundred $(\mathrm{N}=100)$ hip joints of fifty active Police working dogs. It constituted a convenience sample, similar in size to previously published reports on this topic ${ }^{58,67,68}$. Inclusion criteria comprised age over two years, bodyweight over $20 \mathrm{~kg}$, symptomatic in both limbs, with the same OA grade on both hips, and patients should not have received any medication or nutritional supplement for over six weeks. Cases with any other documented or suspected orthopaedic or neurological disease, or any other concomitant disease, were ruled out through physical and radiographic, examination, complete blood count and serum chemistry profile.

After selection, patients were randomly assigned to one of five groups, 10 dogs per group, and treated bilaterally: control group (CG, $n=20$ joints), triamcinolone hexacetonide group (THG, $n=20$ joints), platelet concentrate group (PCG, $n=20$ joints), stanozolol group (SG, $n=20$ joints) and hylan G-F 20 group (HG, $n=20$ 
joints). Evaluations were conducted on days 0 (treatment day), 8, 15, 30, 60, 90, 120, 150 and 180 days post treatment. An outline of all procedures on each moment is presented in Table 4. All evaluations and procedures were performed by the same researcher.

On treatment day, patients in CG received an IA administration of $2 \mathrm{ml}$ of $0.9 \% \mathrm{NaCl}$, given IA. On the same day, patients in THG received an IA administration of $20 \mathrm{mg} / 1 \mathrm{ml}$ of triamcinolone hexacetonide (Bluxam, Riemser Pharma, Portugal). In SG, IA administration of stanozolol (Estrombol, Laboratório Fundacion), at a $0.3 \mathrm{mg} / \mathrm{kg}$ dose was performed ${ }^{69,70}$. Patients in HG received $2 \mathrm{ml}$ of hylan G-F 20 (Synvisc, Sanofi, Portugal). For patients in PCG, $3 \mathrm{ml}$ of platelet concentrate, prepared with the commercially available V-PET kit, according to the manufacturer's instructions, was applied. For the preparation of the platelet concentrate, fifty-five milliliters of whole blood were collected from the jugular vein of the patient and then introduced into the provided closed system. There, the blood flowed by action of gravity through a filter, where the platelets where concentrated. The final platelet concentrate was then collected and was used in the following $5 \mathrm{~min}$ of its preparation.

IA administrations and radiographic examination were conducted under light sedation, induced with a combination of medetomidine $(0.01 \mathrm{mg} / \mathrm{kg})$ and buthorphanol $(0.1 \mathrm{mg} / \mathrm{kg})$, given intravenously. A VD extended legs projection was used, and joints classified according to the Orthopedic Foundation for Animals hip grading scheme $^{14}$. A full description of the OFA hip grading scheme is available online. For the IA administration, patients were placed in lateral recumbency, with the affected limb uppermost. A window of $4 \times 4 \mathrm{~cm}$ in the area surrounding the greater trochanter was clipped and aseptically prepared. The limb was then placed in a neutral position, parallel to the table. A 21-gauge with $2.5^{\prime \prime}$ length needle was then introduced just dorsal to the greater trochanter, perpendicular to the long axis of the limb, until the joint was reached ${ }^{71}$. Confirmation of correct needle placement was obtained through the collection of synovial fluid, and the treatment or saline were administered. Stance analysis was conducted with a weight distribution platform (Companion Stance Analyzer; LiteCure LLC, Newark, Delaware, United States). The equipment was placed in the centre of an observation room, at least 1-m from the walls. Complying with manufacturer's guidelines, the platform was calibrated at the beginning of each testing day and zeroed before each data collection. After an acclimatization period, animals were encouraged to stand on the weight distribution platform. To secure a correct position, the patient's trainer helped to ensure it placed one foot on each quadrant of the platform, while maintaining a natural stance with its their centre of gravity and stability (measured by the platform) near the middle of the platform. When required, gentle restraint was used to maintain the patient's head in a natural, forward-facing position. For all animals, at least 20 measurements were performed, and the mean value was determined. The left-right symmetry index (SI) was calculated according to the following formula: $\mathrm{SI}=\left[\left(\mathrm{WB}_{\mathrm{R}}-\mathrm{WB}_{\mathrm{L}}\right) /\left(\left(\mathrm{WB}_{\mathrm{R}}+\mathrm{WB}_{\mathrm{L}}\right) \times 0.5\right)\right] \times 100^{27,72}$, where $\mathrm{WB}_{\mathrm{R}}$ is the value of weight-bearing for the right pelvic limb and $\mathrm{WB}_{\mathrm{L}}$ is the value of weight-bearing for the left pelvic limb. Negative values were made positive. We also considered deviation from the normal $20 \%$ weight-bearing for a pelvic limb ${ }^{18}$, calculated by subtracting WB to 20 . Before completion of an online copy of the HVAS, CBPI, COI and LOAD, handlers received the published instructions for each of them. The CMIs were completed sequentially by the same handler in each of the follow-up assessments, without knowledge of their previous answers, in a calm room with as much time as needed to answer all items. As CBPI has two section (PSS and PIS), and COI has four dimensions (stiffness, function, gait and QOL), were considered all sections and dimensions in the analysis. After treatment, animals were rested for three consecutive days and resumed their normal activity over a period of 5 days. On days 1 and 3 after the procedure, the veterinarian examined all patients in order to determine possible signs of exacerbated pain, persistent stiffness of gait and changes in posture. If no complaints were registered, the animal could resume its normal activity ${ }^{73,74}$. If a deterioration of the animal's condition was detected, rescue analgesia would be provided and based on the administration of a combination of opioids (tramadol, 2-5 mg/ $\mathrm{kg} \mathrm{BID}$ or TID) and gabapentin (10-20 $\mathrm{mg} / \mathrm{kg}$ TID), as needed.

The outcome considered was as return to or drop below baseline values of SI or deviation and scores of the considered CMIs at the 180-day post treatment. Demographic data consisting of age, sex and body weight, was noted. Results are expressed as mean \pm SD. Kaplan-Meier estimators were conducted to generate survival curves, survival probability and compared with the Breslow test. Cox proportional hazard regression analysis was carried out to investigate the influence of the variables of interest (age, sex, body weight and OFA score) on treatment survival. Treatments were compared to control at initial evaluation with a Wilcoxon signed-rank test. Patients with values or scores above baseline values at 180 days post treatment were censored. All results were analyzed with IBM SPSS Statistics for Windows, Version 20.0. (Armonk, NY: IBM Corp., released 2011) and a significance level of $\mathrm{p}<0.05$ was set.

\section{Data availability}

All data generated or analysed during this study are included in this published article.

Received: 8 May 2020; Accepted: 25 January 2021

Published online: 04 February 2021

\section{References}

1. Loeser, R. F., Goldring, S. R., Scanzello, C. R. \& Goldring, M. B. Osteoarthritis: A disease of the joint as an organ. Arthritis Rheum. 64, 1697-1707 (2012).

2. Anderson, K. L. et al. Prevalence, duration and risk factors for appendicular osteoarthritis in a UK dog population under primary veterinary care. Sci. Rep. 8, 5641 (2018).

3. Torres-Torrillas, M. et al. Adipose-derived mesenchymal stem cells: A promising tool in the treatment of musculoskeletal diseases. Int. J. Mol. Sci. 20, 3105 (2019).

4. Smith, G., Karbe, G., Agnello, K. \& McDonald-Lynch, M. Pathogenesis, diagnosis, and control of canine hip dysplasia. In Veterinary Surgery: Small Animal (eds Tobias, K. \& Johnston, S.) 824-848 (Saunders, New York, 2011). 
5. Kraus, V. B. B. et al. The OARSI histopathology initiative: Recommendations for histological assessments of osteoarthritis in the dog. Osteoarthr. Cartil. 18, S66-S79 (2010).

6. Gregory, M. H. et al. A review of translational animal models for knee osteoarthritis. Arthritis 2012, 1-14 (2012).

7. McCoy, A. M. Animal models of osteoarthritis: Comparisons and key considerations. Vet. Pathol. 52, 803-818 (2015).

8. Kol, A. et al. Companion animals: Translational scientist's new best friends. Sci. Transl. Med. 7, 308-321 (2015).

9. Meeson, R. L., Todhunter, R. J., Blunn, G., Nuki, G. \& Pitsillides, A. A. Spontaneous dog osteoarthritis: A one medicine vision. Nat. Rev. Rheumatol. https://doi.org/10.1038/s41584-019-0202-1 (2019).

10. Pascual-Garrido, C. et al. Canine hip dysplasia: A natural animal model for human developmental dysplasia of the hip. J. Orthop. Res. 36, 1807-1817 (2018).

11. Liu, W. et al. Spontaneous and experimental osteoarthritis in dog: Similarities and differences in proteoglycan levels. J. Orthop. Res. 21, 730-737 (2003).

12. Minnema, L. et al. Correlation of artemin and GFRa3 with osteoarthritis pain: Early evidence from naturally occurring osteoarthritis-associated chronic pain in dogs. Front. Neurosci. 14, 10 (2020).

13. Mayhew, P. D., McKelvie, P. J., Biery, D. N., Shofer, F. S. \& Smith, G. K. Evaluation of a radiographic caudolateral curvilinear osteophyte on the femoral neck and its relationship to degenerative joint disease and distraction index in dogs. J. Am. Vet. Med. Assoc. 220, 472-476 (2002).

14. Puckler, K., Tellhelm, B. \& Kirberger, R. The hip joint and pelvis. In BSAVA Manual of Canine and Feline Musculoskeletal Imaging (eds Kirberger, R. \& McEvoy, F.) 212-231 (Wiley, Hoboken, 2016).

15. Reagan, J. K. Canine hip dysplasia screening within the United States. Vet. Clin. N. Am. Small Anim. Pract. 47, 795-805 (2017).

16. Piel, M. J., Kroin, J. S., Van Wijnen, A. J., Kc, R. \& Im, H. J. Pain assessment in animal models of osteoarthritis. Gene 537, 184-188 (2014).

17. Reid, J., Nolan, A. M. \& Scott, E. M. Measuring pain in dogs and cats using structured behavioural observation. Vet. J. 236, 72-79 (2018).

18. Clough, W., Canapp, S., Taboada, L., Dycus, D. \& Leasure, C. Sensitivity and specificity of a weight distribution platform for the detection of objective lameness and orthopaedic disease. Vet. Comp. Orthop. Traumatol. 31, 391-395 (2018).

19. Lascelles, B. D. X., Brown, D. C., Maixner, W. \& Mogil, J. S. Spontaneous painful disease in companion animals can facilitate the development of chronic pain therapies for humans. Osteoarthr. Cartil. 26, 175-183 (2018).

20. Hyytiäinen, H. K., Mölsä, S. H., Junnila, J. T., Laitinen-Vapaavuori, O. M. \& Hielm-Björkman, A. K. Use of bathroom scales in measuring asymmetry of hindlimb static weight bearing in dogs with osteoarthritis. Vet. Comp. Orthop. Traumatol. 25, 390-396 (2012).

21. Seibert, R., Marcellin-Little, D. J., Roe, S. C., DePuy, V. \& Lascelles, B. D. X. Comparison of body weight distribution, peak vertical force, and vertical impulse as measures of hip joint pain and efficacy of total hip replacement. Vet. Surg. 41, 443-447 (2012).

22. Centre, N. C. G. Osteoarthritis: Care and Management in Adults (Springer, New York, 2014).

23. Cimino Brown, D. What can we learn from osteoarthritis pain in companion animals?. Clin. Exp. Rheumatol. 35(Suppl 1), 53-58 (2017).

24. Stadig, S., Lascelles, B. D. X., Nyman, G. \& Bergh, A. Evaluation and comparison of pain questionnaires for clinical screening of osteoarthritis in cats. Vet. Rec. 185, 757-757 (2019).

25. Gruen, M. E., Griffith, E. H., Thomson, A. E., Simpson, W. \& Lascelles, B. D. X. Criterion validation testing of clinical metrology instruments for measuring degenerative joint disease associated mobility impairment in cats. PLoS ONE 10, e0131839 (2015).

26. Hercock, C. A., Pinchbeck, G., Giejda, A., Clegg, P. D. \& Innes, J. F. Validation of a client-based clinical metrology instrument for the evaluation of canine elbow osteoarthritis. J. Small Anim. Pract. 50, 266-271 (2009).

27. Walton, M. B., Cowderoy, E., Lascelles, D. \& Innes, J. F. Evaluation of construct and criterion validity for the 'Liverpool Osteoarthritis in Dogs' (LOAD) clinical metrology instrument and comparison to two other instruments. PLoS ONE 8, e58125 (2013).

28. Walton, B., Cox, T. \& Innes, J. 'How do I know my animal got better?' Measuring outcomes in small animal orthopaedics. Practice 40, 42-50 (2018).

29. Brown, D. C. The canine orthopedic index. Step 2: Psychometric testing. Vet. Surg. 43, 241-246 (2014).

30. Hudson, J. T., Slater, M. R., Taylor, L., Scott, H. M. \& Kerwin, S. C. Assessing repeatability and validity of a visual analogue scale questionnaire for use in assessing pain and lameness in dogs. Am. J. Vet. Res. 65, 1634-1643 (2004).

31. Wehling, P., Evans, C., Wehling, J. \& Maixner, W. Effectiveness of intra-articular therapies in osteoarthritis: A literature review. Ther. Adv. Musculoskelet. Dis. 9, 183-196 (2017).

32. Céleste, C., Ionescu, M., Poole, A. R. \& Laverty, S. Repeated intraarticular injections of triamcinolone acetonide alter cartilage matrix metabolism measured by biomarkers in synovial fluid. J. Orthop. Res. 23, 602-610 (2005).

33. Garg, N., Perry, L. \& Deodhar, A. Intra-articular and soft tissue injections, a systematic review of relative efficacy of various corticosteroids. Clin. Rheumatol. 33, 1695-1706 (2014).

34. Zhang, W. et al. OARSI recommendations for the management of hip and knee osteoarthritis, Part II: OARSI evidence-based, expert consensus guidelines. Osteoarthr. Cartil. 16, 137-162 (2008).

35. Park, K. D. et al. Ultrasound guided intra-articular ketorolac versus corticosteroid injection in osteoarthritis of the hip: A retrospective comparative study. Skeletal Radiol. 44, 1333-1340 (2015).

36. Sánchez, M., Anitua, E., Azofra, J., Aguirre, J. J. \& Andia, I. Intra-articular injection of an autologous preparation rich in growth factors for the treatment of knee OA: A retrospective cohort study. Clin. Exp. Rheumatol. 26, 910-913 (2008).

37. Cole, B. J., Seroyer, S. T., Filardo, G., Bajaj, S. \& Fortier, L. A. Platelet-rich plasma: Where are we now and where are we going?. Sport. Health A Multidiscip. Approach 2, 203-210 (2010).

38. Hammond, J. W., Hinton, R. Y., Curl, L. A., Muriel, J. M. \& Lovering, R. Use of autologous platelet-rich plasma to treat muscle strain injuries. Am. J. Sport. Med. 37, 1135-1142 (2009).

39. Nguyen, R. T., Borg-Stein, J. \& McInnis, K. Applications of platelet-rich plasma in musculoskeletal and sports medicine: An evidence-based approach. $P M \ll R$ 3, 226-250 (2011).

40. Fernández, L. et al. Stanozolol and danazol, unlike natural androgens, interact with the low affinity glucocorticoid-binding sites from male rat liver microsomes. Endocrinology 134, 1401-1408 (1994).

41. Wright, J. K., Smith, A. J., Cawston, T. E. \& Hazleman, B. L. The effects of the anabolic steroid, stanozolol, on the production of procollagenase by human synovial and skin fibroblasts in vitro. Agents Actions 28, 279-282 (1989).

42. Spadari, A. et al. Effects of intraarticular treatment with stanozolol on synovial membrane and cartilage in an ovine model of osteoarthritis. Res. Vet. Sci. 94, 379-387 (2013).

43. Spadari, A., Rinnovati, R., Babbini, S. \& Romagnoli, N. Clinical evaluation of intra-articular administration of Stanozolol to manage lameness associated with acute and chronic osteoarthritis in horses. J. Equine Vet. Sci. 35, 105-110 (2015).

44. Rinnovati, R., Romagnoli, N. \& Spadari, A. Dose-finding study for intraarticular treatment with Stanozolol in horses. J. Equine Vet. Sci. 35, 860-864 (2015).

45. Martins, M. C., Peffers, M. J., Lee, K. \& Rubio-Martinez, L. M. Effects of stanozolol on normal and IL-1 $\beta$-stimulated equine chondrocytes in vitro. BMC Vet. Res. 14, 1-7 (2018).

46. Gigante, A. \& Callegari, L. The role of intra-articular hyaluronan (Sinovial) in the treatment of osteoarthritis. Rheumatol. Int. 31, 427-444 (2011).

47. Evans, C. H. Novel biological approaches to the intra-articular treatment of osteoarthritis. BioDrugs 19, 355-362 (2005). 
48. Colen, S., van den Bekerom, M. P., Bellemans, J. \& Mulier, M. Comparison of intra-articular injections of Hyaluronic Acid and Corticosteroid in the treatment of Osteoarthritis of the hip in comparison with intra-articular injections of Bupivacaine. Design of a prospective, randomized, controlled study with blinding. BMC Musculoskelet. Disord. 11, 264 (2010).

49. Strauss, E. J., Hart, J. A., Miller, M. D., Altman, R. D. \& Rosen, J. E. Hyaluronic acid viscosupplementation and osteoarthritis. Am. J. Sports Med. 37, 1636-1644 (2009).

50. Aggarwal, A. \& Sempowski, I. P. Hyaluronic acid injections for knee osteoarthritis: Systematic review of the literature. Can. Fam. Physician 50, 249-256 (2004).

51. Cheng, O. T., Souzdalnitski, D., Vrooman, B. \& Cheng, J. Evidence-based knee injections for the management of arthritis. Pain Med. 13, 740-753 (2012).

52. Vina, E. R. \& Kwoh, C. K. Epidemiology of osteoarthritis. Curr. Opin. Rheumatol. 30, 160-167 (2018).

53. Mendes, J. G. et al. Comparison between intra-articular Botulinum toxin type A, corticosteroid, and saline in knee osteoarthritis: a randomized controlled trial. Clin. Rehabil. 33, 1015-1026 (2019).

54. Weitoft, T. \& Öberg, K. Dosing of intra-articular triamcinolone hexacetonide for knee synovitis in chronic polyarthritis: a randomized controlled study. Scand. J. Rheumatol. 48, 279-283 (2019).

55. Cushman, D. M. et al. Comparison of varying corticosteroid type, dose, and volume for the treatment of pain in small- and intermediate-size joint injections: A narrative review. $P M \diamond R$ 11, 758-770 (2019).

56. Fahie, M. A. et al. A randomized controlled trial of the efficacy of autologous platelet therapy for the treatment of osteoarthritis in dogs. J. Am. Vet. Med. Assoc. 243, 1291-1297 (2013).

57. Alves, J. C., Santos, A., Jorge, P., Lavrador, C. \& Carreira, L. M. A report on the use of a single intra-articular administration of autologous platelet therapy in a naturally occurring canine osteoarthritis model: A preliminary study. BMC Musculoskelet. Disord. 21, 127 (2020).

58. Pashuck, T. D., Kuroki, K., Cook, C. R., Stoker, A. M. \& Cook, J. L. Hyaluronic acid versus saline intra-articular injections for amelioration of chronic knee osteoarthritis: A canine model. J. Orthop. Res. 34, 1772-1779 (2016).

59. Cubukcu, D., Sarsan, A. \& Alkan, H. Relationships between pain, function and radiographic findings in osteoarthritis of the knee: A cross-sectional study. Arthritis 2012, 1-5 (2012).

60. Khairina, A. D., Moeliono, M. A. \& Rahmadi, A. R. Correlation between radiographic grading of osteoarthritis, pain severity and functional status in knee osteoarthritis patients. Althea Med. J. 5, 43-46 (2018).

61. Previtali, D. et al. The long-lasting effects of "placebo injections" in knee osteoarthritis: A meta-analysis. Cartilage https://doi. org/10.1177/1947603520906597 (2020).

62. Weiss, E. Knee osteoarthritis, body mass index and pain: data from the osteoarthritis initiative. Rheumatology 53, 2095-2099 (2014).

63. Ornetti, P. et al. Does platelet-rich plasma have a role in the treatment of osteoarthritis?. Jt. Bone Spine 83, 31-36 (2016).

64. Popma, J. W. et al. Comparison of 2 dosages of intraarticular triamcinolone for the treatment of knee arthritis: Results of a 12 -week randomized controlled clinical trial. J. Rheumatol. 42, 1865-1868 (2015).

65. Joseph, G. B. et al. Do persons with asymmetric hip pain or radiographic hip OA have worse pain and structure outcomes in the knee opposite the more affected hip? Data from the Osteoarthritis Initiative. Osteoarthr. Cartil. 24, 427-435 (2016).

66. Shakoor, N. et al. Asymmetries and relationships between dynamic loading, muscle strength, and proprioceptive acuity at the knees in symptomatic unilateral hip osteoarthritis. Arthritis Res. Ther. 16, 455 (2014).

67. Yun, S., Ku, S.-K. \& Kwon, Y.-S. Adipose-derived mesenchymal stem cells and platelet-rich plasma synergistically ameliorate the surgical-induced osteoarthritis in Beagle dogs. J. Orthop. Surg. Res. 11, 9 (2016).

68. Scott, R. M., Evans, R. \& Conzemius, M. G. Efficacy of an oral nutraceutical for the treatment of canine osteoarthritis. Vet. Comp. Orthop. Traumatol. 30, 318-323 (2017).

69. Cotta, J. et al. Estudo Preliminar Para a Avaliação da Eficácia Clínica das Infiltrações Intra-articulares com Estanozolol em Canídeos com Doença Degenerativa Articular e a Sua Relaçõa Com a Interleucina-1ß Sérica (University of Lisbon, Lisbon, 2016).

70. Adamama-Moraitou, K. K. et al. Conservative management of canine tracheal collapse with stanozolol: A double blinded, placebo control clinical trial. Int. J. Immunopathol. Pharmacol. 24, 111-118 (2011).

71. Van Vynckt, D. et al. The use of intra-articular anesthesia as a diagnostic tool in canine lameness. Vlaams Diergeneeskd. Tijdschr. 81, 290-297 (2012).

72. Volstad, N., Sandberg, G., Robb, S. \& Budsberg, S. The evaluation of limb symmetry indices using ground reaction forces collected with one or two force plates in healthy dogs. Vet. Comp. Orthop. Traumatol. 30, 54-58 (2017).

73. Caron, J. P. Intra-articular injections for joint disease in horses. Vet. Clin. N. Am. Equine Pract. 21, 559-573 (2005).

74. Chakravarty, K., Pharoah, P. D. P. \& Scott, D. G. I. A randomized controlled study of post-injection rest following intra-articular steroid therapy for knee synovitis. Rheumatology 33, 464-468 (1994).

\section{Acknowledgements}

The authors would like to thank Manuel Pereira for the help in the preparation of this manuscript and statistical analysis of the data, the Pall Corporation for providing the V-PET kits and Companion, LiteCure LLC, for providing the Stance Analyser used in this study.

\section{Author contributions}

J.C.A. designed the protocol, conducted treatments and prepared the manuscript. P.J. and A.S. selected patients and conducted treatments. C.L. and L.M.C. revised the protocol and prepared the manuscript. All authors have read and approved the manuscript.

\section{Competing interests}

The V-PET kits used in this study were provided by the Pall Corporation and the Stance Analyser used in this study was provided by Companion, LiteCure LLC.

\section{Additional information}

Correspondence and requests for materials should be addressed to J.C.A.

Reprints and permissions information is available at www.nature.com/reprints.

Publisher's note Springer Nature remains neutral with regard to jurisdictional claims in published maps and institutional affiliations. 
(c) (i) Open Access This article is licensed under a Creative Commons Attribution 4.0 International cc) License, which permits use, sharing, adaptation, distribution and reproduction in any medium or format, as long as you give appropriate credit to the original author(s) and the source, provide a link to the Creative Commons licence, and indicate if changes were made. The images or other third party material in this article are included in the article's Creative Commons licence, unless indicated otherwise in a credit line to the material. If material is not included in the article's Creative Commons licence and your intended use is not permitted by statutory regulation or exceeds the permitted use, you will need to obtain permission directly from the copyright holder. To view a copy of this licence, visit http://creativecommons.org/licenses/by/4.0/.

(C) The Author(s) 2021 